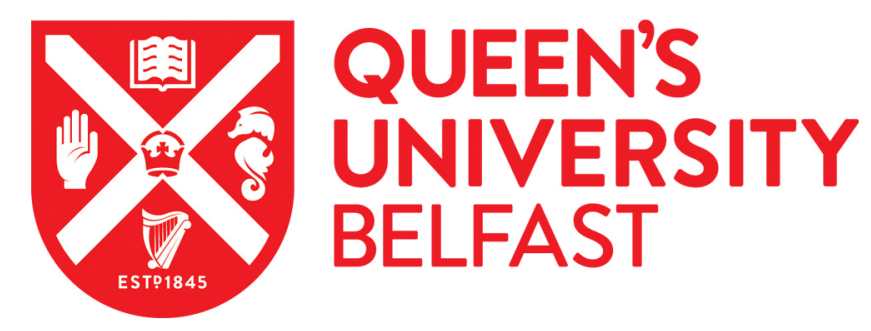

\title{
Anti-biofilm activity of ultrashort cinnamic acid peptide derivatives against medical device-related pathogens
}

Laverty, G., McCloskey, A. P., Gorman, S. P., \& Gilmore, B. F. (2015). Anti-biofilm activity of ultrashort cinnamic acid peptide derivatives against medical device-related pathogens. Journal of peptide science, 21(10), 770-778. https://doi.org/10.1002/psc.2805

Published in:

Journal of peptide science

Document Version:

Peer reviewed version

Queen's University Belfast - Research Portal:

Link to publication record in Queen's University Belfast Research Portal

\section{Publisher rights}

Copyright $\odot 2015$ European Peptide Society and John Wiley \& Sons, Ltd.

This is the peer reviewed version of the following article: Laverty, G., McCloskey, A. P., Gorman, S. P., and Gilmore, B. F. (2015) Anti-biofilm activity of ultrashort cinnamic acid peptide derivatives against medical device-related pathogens. J. Pept. Sci., 21: 770-778., which has been published in final form at http://onlinelibrary.wiley.com/doi/10.1002/psc.2805/abstract. This article may be used for non-commercial purposes in accordance with Wiley Terms and Conditions for Self-Archiving.

\section{General rights}

Copyright for the publications made accessible via the Queen's University Belfast Research Portal is retained by the author(s) and / or other copyright owners and it is a condition of accessing these publications that users recognise and abide by the legal requirements associated with these rights.

\section{Take down policy}

The Research Portal is Queen's institutional repository that provides access to Queen's research output. Every effort has been made to ensure that content in the Research Portal does not infringe any person's rights, or applicable UK laws. If you discover content in the Research Portal that you believe breaches copyright or violates any law, please contact openaccess@qub.ac.uk. 
Antibiofilm activity of ultrashort cinnamic acid peptide derivatives against medical device related pathogens

Peptide-cinnamon hybrids eradicate resistant biofilm pathogens

Garry Laverty*, Alice P. McCloskey, Sean P. Gorman, Brendan F. Gilmore

Biomaterials, Biofilm and Infection Control Research Group,

School of Pharmacy, Queens University of Belfast, Medical Biology Centre, 97 Lisburn Road, Belfast, BT9 7BL, UK

*Author for Correspondence

Dr Garry Laverty

Queen’s University of Belfast, Medical Biology Centre,

97 Lisburn Road,

Belfast BT9 7BL, UK

Tel: +44 (0) 2890972273

Fax: +44 (0) 2890247794

Email: garry.laverty@qub.ac.uk 


\section{Abstract}

The threat of antimicrobial resistance has placed increasing emphasis on the development of innovative approaches to eradicate multi-drug resistant pathogens. Biofilm forming microorganisms, for example Staphylococcus epidermidis and Staphylococcus aureus, are responsible for increased incidence of biomaterial infection, extended hospital stays and patient morbidity and mortality. This paper highlights the potential of ultrashort tetra-peptide conjugated to hydrophobic cinnamic acid derivatives. These peptidomimetic molecules demonstrate selective and highly potent activity against resistant biofilm forms of the Grampositive medical device related pathogens. 3-(4-hydroxphenylpropionic)-Orn-Orn-Trp-Trp$\mathrm{NH}_{2}$ displays particular promise with minimum biofilm eradication concentration (MBEC) values of $125 \mu \mathrm{g} / \mathrm{mL}$ against methicillin sensitive (ATCC 29213) and resistant (ATCC 43300) S. aureus and activity shown against biofilm forms of Escherichia coli (MBEC: 1000 $\mathrm{gg} / \mathrm{mL}$ ). Kill kinetics confirms complete eradication of established 24 hour biofilms at MBEC with 6 hours exposure. Reduced cell cytotoxicity, relative to Gram-positive pathogens, was proven via tissue culture (HaCaT) and a haemolysis assays (equine erythrocytes).

Existing as in nature as part of the immune response, antimicrobial peptides display great promise for exploitation by the pharmaceutical industry in order to increase the library of available therapeutic molecules. Ultrashort variants are particularly promising for translation as clinical therapeutics as they are more cost-effective, easier to synthesise and can be tailored to specific functional requirements based on the primary sequence allowing factors such as spectrum of activity to be varied.

Keywords: Antimicrobial, Biofilm, MBEC, Biomaterials, Peptide, Kill kinetics

\section{Introduction}

Increasing resistance to current antimicrobials is one of the most pressing issues impacting society. Resistant infections are responsible for high rates of morbidity and mortality, causing significant suffering to patients, their family and carers. As resistance to antimicrobials increases so too does the possibility of an age were procedures such as joint replacements, caesarean sections, chemotherapy, implants and transplant surgery are not possible and simple infections kill. Medical devices have an increasingly important role in patient care. An estimated 5 million medical devices, for example catheters and hip replacements, are implanted each year in the United States [1]. This is due to an increasingly elderly population within modern society and a greater demand for technologies to replace the normal 
physiological functions of the human body.. The medical device provides an optimal surface for the formation of microbial biofilm. This protective biofilm matrix results in an infection 10-1000 times more resistant to standard chemotherapy often resulting in failure of both device and antimicrobial therapy, leading to removal of the implant. As concerns regarding resistance increase there is an urgent need for new antimicrobials that are active against an increasing spectrum of pathogens resistant to commonly used therapeutic regimens.

One potential source of novel antimicrobials may be in nature itself with a recent increase in focus on traditional therapies to aid chronic and acute disease states. Included in these range of remedies are essential oils; traditional remedies for relief of the common cold, acute sinusitis and respiratory tract infections. Research by Ioannou demonstrated oils from cinnamon bark to be amongst the most microbicidal naturally occurring compounds [2]. Antimicrobial peptides serve as an alternative source of therapeutics. A diverse reservoir of peptides exist in nature with potent activity shown against a broad range of microorganisms via multiple modes of action [3]. Further research has allowed the identification of a structural pharmacophore (two units of hydrophobic bulk and two of charge) that acts as the minimum motif to provide antimicrobial action [4]. Recently, Bisht et al produced a series of amino terminal modified peptides containing two ornithine (providing charge) and two tryptophan residues (providing bulk) with significantly reduced minimum inhibitory concentration (MIC) values for amino terminal peptides in comparison to C-terminal carboxylic acids [5]. This original research paper outlines the activity of a range of ultrashort cinnamic acid peptide derivatives against a variety of clinically relevant biofilm forms of pathogens implicated in medical device related infection. Their cytotoxicity is compared via tissue culture (HaCaT) and haemolysis assays.

\section{Materials and Methods}

\section{Peptide synthesis}

Cinnamic acid, 3,5-dimethoxy-4-hydroxycinnamic acid, 3-(4-hydroxphenylpropionic) acid, p-anisic acid and 6-maleimidocaproic acid were obtained from Sigma-Aldrich (Dorset, UK). 9-fluorenylmethoxy carbonyl (Fmoc) L-amino acids, Rink amide 4-(2',4'-dimethoxyphenylFmoc-aminomethyl)-phenoxyacetamido-MHBA (MHBA) resin and 2-(1H-benzotriazole-1yl)-1,1,3,3-tetramethyluronium hexafluorophosphate (HBTU) were obtained from Merck Chemicals Ltd (Nottingham, UK). All other reagents were peptide synthesis grade. Peptides were synthesised via standard Fmoc solid phase protocols using a CEM Liberty microwave 
enhanced automated peptide synthesiser ( $1 \mathrm{mmol}$ scale) and are outlined in Figure 1. Peptides were cleaved from the resin by a mixture of 95\% trifluroacetic acid (TFA), $2.5 \%$ trisopropylsilane and $2.5 \%$ thioanisole (2 hours, room temperature). The identity of each peptide was confirmed via mass spectroscopy (Finnigan LCQ Ion Trap Mass Spectrometer). Peptide purity was analysed via reverse-phase HPLC using an Agilent 1260 Infinity system, fitted with a Gemini C18, $250 \mathrm{~mm} \times 4.6 \mathrm{~mm}$ column, a 2-60\% acetonitrile gradient [30 min] in $0.05 \%$ TFA water at a flow rate of $1.5 \mathrm{~mL} / \mathrm{min}$. All peptides were found to have $>90 \%$ purity.

\section{Microorganisms, strains and culture conditions}

Biofilm forming medical device related pathogens tested were as follows: methicillin resistant S. epidermidis (MRSE) (ATCC 35984), methicillin sensitive S. aureus (ATCC 29213), methicillin resistant S. aureus (MRSA) (ATCC 43300), E. coli (NCTC 8196) and Candida tropicalis (NCTC 7393). Microorganisms were subcultured in Müeller-Hinton broth (MHB) prior to testing.

\section{Determination of MIC, minimum bactericidal (MBC)/fungicidal concentration (MFC)}

Broth microdilution tests were performed according to CLS guidelines as described previously by our group in 96-well microtitre plates [6]. Peptides were dissolved in MHB and sterility ensured by passing through a $0.22 \mu \mathrm{m}$ sterile filter. Peptides were tested over the concentration range $1000-3.91 \mu \mathrm{g} / \mathrm{mL}$ with MIC determined visually after 24 hour incubation at $37^{\circ} \mathrm{C}$. MBC/MFC were determined by inoculating Müeller-Hinton agar (MHA) plates with wells that demonstrated inhibited growth (clear wells). Plates were incubated at $37^{\circ} \mathrm{C}$ for 24 hour and observed for 99.9\% kill.

\section{Planktonic kill kinetics}

The ability of peptides to kill planktonic isolates were evaluated as previously outlined [7]. A concentration of four times the MIC for each peptide allowed for effective analysis of the kill kinetics of each antimicrobial. Time points selected to assess planktonic kill kinetics were 10 minutes (0.1667 hours), 1, 1.5, 2, 4, 6 and 24 hours and five replicates studied. $20 \mu \mathrm{L}$ aliquots were removed at each time point and serially diluted in universal neutraliser [7]. Viable colony counts, recorded as colony forming units per millitre (CFU/mL), were obtained by Miles and Misra technique via plating on MHA and incubating for 24 hours at $37^{\circ} \mathrm{C}$. 


\section{Minimum Biofilm Eradication Concentration (MBEC) determination}

The ability of each peptide to eradicate established 24 hour single special biofilms was assessed using the Calgary Biofilm Device (MBEC Assay for Physiology \& Genetics (P\&G), Innovotech Inc., Alberta, Canada) by a method developed fully and previously described by our group [6]. Biofilms were challenged with each individual peptide $(1000-3.91 \mu \mathrm{g} / \mathrm{mL})$ for 24 hours with six replicates at each concentration. After treatment a recovery plate was formed by addition of $200 \mu \mathrm{L}$ of MHB to each well of a separate 96-well microtitre plate and incubating the treated MBEC lid (containing pegs) for 24 hours. The plate was examined visually and the lowest concentration with no visual growth for each peptide was designated as the MBEC.

\section{Biofilm kill kinetics}

Biofilm eradication was evaluated over 24 hours using a Calgary Biofilm Device and a method developed previously by our group [7]. If deemed active (MBEC $\leq 1000 \mu \mathrm{g} / \mathrm{mL}$ ) established 24 hour biofilms of each susceptible microorganism (single species) were challenged with the MBEC of each peptide. Peptides deemed non-active (MBEC $>1000 \mu \mathrm{g} / \mathrm{mL}$ ) and outside the tested concentration range, were not tested for biofilm eradication kinetics. Cinnamic-Orn-Orn-Trp-Trp- $\mathrm{NH}_{2}$, 3,5-dimethoxy-4-hydroxycinnamicOrn-Orn-Trp-Trp-NH $\mathrm{NH}_{2}$ p-anisic-Orn-Orn-Trp-Trp- $\mathrm{NH}_{2}$ and 6-maleimidocaproic-Orn-OrnTrp-Trp- $\mathrm{NH}_{2}$ had MBEC values greater than $1000 \mu \mathrm{g} / \mathrm{mL}$ (Table 1) against Pseudomonas aeruginosa (PAO1), E. coli (NCTC 8196) and C. tropicalis (NCTC 7393) and therefore were not tested for biofilm eradication kinetics. The same is true for 3-(4-hydroxphenylpropionic)Orn-Orn-Trp-Trp- $\mathrm{NH}_{2}$ against $P$. aeruginosa (PAO1). Time points selected for assessment were $0.5,1,1.5,2,3,4,6$ and 24 hours. At the designated time-points five pegs were removed from the Calgary Biofilm Device using sterile flamed pliers and placed into separate wells of a dilution plate containing universal neutraliser. Negative controls at each timepoint (five replicates) were represented by Phosphate Buffered Saline (PBS) only. Viable colony counts (CFU/mL) were obtained for each time-point by serial dilution and plating on MHA (Miles and Misra, 24 hour incubation, $37^{\circ} \mathrm{C}$ ).

\section{Cell cytotoxicity}

HaCaT cell lines (collection number: 400693) were purchased from Cell Line Services (Eppelheim, Germany), cultured in Dulbecco's Modified Eagle's Medium (DMEM) containing $4500 \mathrm{mg} / \mathrm{L}$ D-glucose from Invitrogen (Paisley, UK) supplemented with $2 \mathrm{mM} \mathrm{L-}$ 
glutamine foetal bovine serum and $1 \%$ penicillin/streptomycin. Cells were grown at $37{ }^{\circ} \mathrm{C} / 5$ $\% \mathrm{CO}_{2}$ and subcultured until $90 \%$ confluency. Cell viability was assessed quantitatively via a 3-[4,5-dimethylthiazol-2-yl]-2,5-diphenyltetrazolium bromide (MTT) assay as previously outlined [6]. HaCaT cells were cultured until at third passage and inoculated $\left(1 \times 10^{4}\right.$ cells/well) into 96 -well microtitre plates at $37^{\circ} \mathrm{C} / 5 \% \mathrm{CO}_{2}$ for $24 \pm 1$ hour, until approximately 90\% confluency. Media was removed and replaced with fresh growth medium (excluding penicillin/streptomycin) containing doubling dilutions of each peptide in the concentration range 1000 to $3.91 \mu \mathrm{g} / \mathrm{ml}$. Cells were tested for $24 \pm 1$ hour, after which $10 \mu \mathrm{g} / \mathrm{ml}$ sterile MTT reagent was added to each well (sterility ensured by passing through $20 \mu \mathrm{M}$ filter). Cells were incubated for 24 hours at $37^{\circ} \mathrm{C} / 5 \% \mathrm{CO}_{2}$, culture medium was removed, and insoluble intracellular formazan crystals dissolved with $200 \mu \mathrm{L}$ dimethyl sulfoxide. Absorption was measured spectrophotometrically at $570 \mathrm{~nm}$ using a Tecan Sunrise ${ }^{\circledR}$ plate reader. Cells treated with $70 \%$ ethanol represented positive kill controls ( $0 \%$ viability) and PBS acted as a negative control (100\% viability). Percentage cell viability was calculated relative to untreated control wells, taking into account subtraction of the blank value corresponding to untreated cells (MTT absent). Results are reported as the mean of six replicates.

\section{Haemolysis assay}

Peptides were assayed for their ability to induce haemoglobin release from fresh equine erythrocytes as previously outlined [6]. Fresh defibrinated equine erythrocytes (Laboratory Supplies \& Instruments Ltd., Antrim, UK) were washed three times with equal volumes of PBS and centrifuged for 15 minutes at $900 \mathrm{~g}$. Erythrocytes were resuspended 4\% (volume/volume) in PBS and 100 $\mu \mathrm{L}$ of erythrocyte suspension added to each well of a 96well microtitre plate. Erythrocytes were exposed to doubling dilutions of peptide (1000$3.91 \mu \mathrm{g} / \mathrm{mL}$ ), incubated at $37^{\circ} \mathrm{C}$ for 1 hour and centrifuged at $1000 \mathrm{~g}$. Supernatants were transferred to a fresh 96-well microtitre plate, and haemoglobin release determined at $405 \mathrm{~nm}$ using a Tecan Sunrise ${ }^{\circledR}$ plate reader. Erythrocytes treated with $0.1 \%$ Triton X-100 represented positive controls (100\% haemolysis) and PBS (0\% haemolysis) acted as a negative control. Results are reported as the mean of six replicates.

Percentage haemolysis was calculated as follows in equation 1 :

$$
\% \text { Haemolysis }=\frac{(\text { Abs405 peptide treatment })-(\text { Abs405 PBS })}{(\text { Abs405 0.1\%TritonX }-100)-(\text { Abs } 405 P B S)}
$$




\section{Statistical Analysis}

Statistical analyses were carried out using GraphPad Prism 6. Rate of biofilm eradication (biofilm viable count ( $\left.\log _{10} \mathrm{CFU} / \mathrm{peg}\right)$ at each time point) and planktonic rate of kill ( $\log _{10}$ planktonic viable counts ( $\left.\log _{10} \mathrm{CFU} / \mathrm{mL}\right)$ ) for each peptide was examined using a KruskallWallis test, with a Dunn's post-hoc test used to identify individual differences relative to the untreated control (PBS) for each peptide at each timepoint. These tests were also utilised for statistical analysis of tissue culture and haemolysis cytotoxicity data whereby percentage viability/haemolysis for the peptides employed were also compared to the untreated (PBS) control (100\% viability/0\% haemolysis). Data was shown to be non-normally distributed using the Kolmogorov and Smirnov method, therefore validating the selection of the nonparametric Kruskal-Wallis test. In all cases a probability of $\mathrm{p}<0.05$ denoted significance.

\section{Results and Discussion}

For ultrashort peptide derivatives, antimicrobial activity is clearly influenced by the nature of the N-terminal substituent [6]. Activity against the selected planktonic isolates, Grampositive S. aureus and Gram-negative P.aeruginosa and E. coli, were consistent with those determined by Bisht and colleagues [5]. For example MIC values obtained by Bisht et al against S. aureus, P. aeruginosa and E. coli were reported to be 128, 256 and $256 \mu \mathrm{g} / \mathrm{mL}$ respectively. Values obtained by our group (Table 1) display similar correlation (125, 250 and $250 \mu \mathrm{g} / \mathrm{mL}$ ). Carboxylic acid derivatives of cinnamon extracts were conjugated to the amino terminus to provide further bulk (increasing the lipophilic:charge ratio) and increasing antimicrobial activity.

Cinnamic acid and its structural derivatives are phenolic acids. They are highly lipophilic, possess anti-oxidant effects, act as chelators and free radical scavengers, and demonstrate inherent antimicrobial activity [8]. Examples include ethanolic extracts obtained from exotic plants, such as Onosma hispidum, which are associated with the herbal treatment of infection and burns [9]. The antimicrobial effects of traditional medicines such as the Iranian folk medicine propolis have been attributed to phenolic acids, more specifically; 3,4dimethoxycinnamic acid [10]. Related compounds have also generated interest as potential agents against tuberculosis and its causative microorganism Mycobacterium tuberculosis. Cinnamic acid-based derivatives have been proven to inhibit the fatty acid synthase type II system of M. tuberculosis, a process essential for the organism's survival [11]. The antibacterial activity of cinnamic acid derivative's may be due to inhibition of the bacterial 
cell division protein FtsZ. FtsZ is the key protein of the contractile ring that forms between at the bacterial membrane before cell division and cinnamic acid inhibits bacterial replication by prevention of its assembly [12]. Truchado et al hypothesised that honey containing hydroxy cinnamic acid (similar to 3-(4-hydroxphenyl)propionic acid) may exert its antibacterial action by inhibition of quorum sensing pathways [13]. These compounds may therefore provide benefit in preventing biofilm formation in both Gram-positive and negative bacteria via inhibition of oligopeptides and acylated homoserine lactones respectively, with potential benefits for the prevention of medical device related infection.

Cinnamic peptides demonstrate increased selectivity for Gram-positive bacteria MRSE (Figure 2), S.aureus (Figure 3) and MRSA (Figure 4). The addition of 3-(4hydroxphenyl)propionic acid to the tetrapeptide motif ( ${ }_{2} \mathrm{HN}-\mathrm{Orn}-\mathrm{Orn}-\mathrm{Trp}-\mathrm{Trp}-\mathrm{NH}_{2}$ ) increased anti-biofilm activity against 24 hour established biofilms of Gram-negative E. coli and the fungi C. tropicalis (MBEC values: $1000 \mu \mathrm{g} / \mathrm{mL}$, Table 1), with complete eradication of the biofilm demonstrated within 24 hours (Figure 5 and 6). Gram-negative bacteria show an increased resistance to the antibacterial action of essential oils, in comparison to Grampositives due to the presence of an outer membrane consisting of hydrophilic polysaccharide chains as a barrier to the mainly hydrophobic character of essential oils [14]. The presence of a hydroxy grouping on the 3-(4-hydroxphenyl)propionic moiety (Figure 1, structure 3) may allow for increased hydrophilic interaction with outer membrane polysaccharides and therefore greater activity against Gram-negative bacteria. The importance of this hydroxy grouping in enabling a suitable reduction in the lipohilic:charge balance to allow interaction with hydrophilic Gram-negative outer membrane polysaccharides is further shown by the activity of 3-(4-hydroxphenylpropionic)-Orn-OrnTrp-Trp- $\mathrm{NH}_{2}$ against the planktonic form of P. aeruginosa (MIC, MBC, Table 1).

Related lipophilic moieties provide similar antimicrobial benefits when attached to the tetrapeptide motif. 3,5-dimethoxy-4-hydroxycinnamic acid, commonly known as sinapic or sinapinic acid, demonstrate antibacterial activity against Gram-negative E.coli due to the presence of two methoxyl and one hydroxyl grouping (Figure 1, structure 2) [15]. Such groupings have a high affinity for bacterial proteins and specifically enzymes, with the presence of at least one phenolic hydroxyl group and a certain degree of lipophilicity shown to provide antimicrobial character [16]. Although antimicrobial activity is demonstrated for 3,5-dimethoxy-4-hydroxycinnamic-Orn-Orn-Trp-Trp- $\mathrm{NH}_{2}$ against planktonic forms of E. coli 
and $P$. aeruginosa (MIC and MBC values both $250 \mu \mathrm{g} / \mathrm{mL}$ for each, Table 1 ) it is more selective for Gram-positive microorganisms, a pattern that correlates to all peptides tested. The increased hydrophilicity provided by the two methoxyl and one hydroxyl grouping on the 3,5-dimethoxy-4-hydroxycinnamic is negated by the presence of the cationic peptide moiety that favours interaction and activity against Gram-positive bacteria and its membrane [17].

Another plant extract containing a methoxy grouping that demonstrates antimicrobial action in the literature is $p$-anisic acid. Originating from sources such as aniseed (Pimpinella anisum), $p$-anisic acid alone displays $\mathrm{mg} / \mathrm{mL}$ activity against resistant bacterial strains such as MRSA [18]. Conjugation to the tetrapeptide motif increases activity of the $p$-anisic grouping

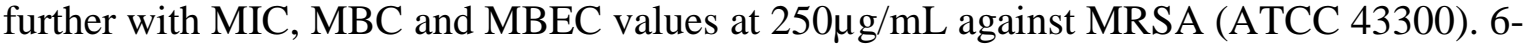
maleimidocaproic acid was selected as an alternative amino terminal moiety to the cinnamic acid derivatives. 6-maleimidocaproic acid is commonly used as a peptide probe for identifying thiol groups present within cell membranes, binding with cell membrane bound proteins with high affinity [19]. Its ability to increase interactions with microbial membrane bound proteins was hypothesised to allow the antimicrobial peptide motif to exert a greater antimicrobial action at the membrane interface. The structure of 6-maleimidocaproic acid may also provide antimicrobial activity in itself due to the presence of two highly electronegative oxygen atoms and a nitrogen supplying charge, balanced by a lipophilic hydrocarbon tail (Figure 1, structure 5). However in the majority of cases, the addition of a terminal 6-maleimidocaproic grouping to the ornithine and tryptophan containing backbone provided no advantage in terms of lowering MIC, MBC or MBEC values when compared to results obtained previously with the amino terminal tetrapeptide $\left(\mathrm{H}_{2} \mathrm{~N}\right.$-Orn-Orn-Trp-Trp$\mathrm{NH}_{2}$ ) alone [6]. The addition of 6-maleimidocaproic only showed any particular benefit against the fungus $C$. tropicalis with MIC and MFC values halved (MIC: 125 to $62.5 \mu \mathrm{g} / \mathrm{mL}$, MFC: 250 to $125 \mu \mathrm{g} / \mathrm{mL}$ ) with the presence of an additional lipophilic tail possibly enhancing the antifungal action and structure activity relationship of the peptide motif [20].

Kill kinetics were assessed against planktonic microorganisms at four times the MIC value. The selection of an antimicrobial concentration of four times the MIC allowed for effective analysis of the kill kinetics (bactericidal). Rapid cidal action was demonstrated for all peptides with total kill of planktonic microorganisms within 10 minutes exposure (Table S2). These results prove a rapid bactericidal effect is achieved within minutes against planktonic 
forms of Gram-positive and negative bacteria and also fungi, likely due to targeting of cellular membranes [21]. The mechanism of action of these cationic peptides is mainly due to cidal not inhibitory action. The potential for resistance developing is lessened further by many antimicrobial peptides possessing similar MIC and MBC values [22]. Many of the MIC and MBC values obtained (Table 1) correlate or are within one dilution of each other. For Gram-positive microorganisms MBEC values often compare to MIC and MBC values. This indicates that these antimicrobial peptides are highly effective with eradication of the biofilm matrix and planktonic cells occurring at similarly low concentrations. The peptides tested possessed rapid kill kinetics (all within 6 hours) at MBEC values against mature 24 hour biofilms of the Gram-positive bacteria MRSE (ATCC 35984), S. aureus (ATCC 29213) and MRSA (ATCC 43300). Such rapid kill is indicative of the ability of these peptides to break down the extracellular polysaccharide matrix of staphylococci and in particular exopolysaccharide intercellular adhesion, that has been shown to increase the resistance of $S$. epidermidis to other antimicrobial peptides including human $\beta$-defensin 3, LL-37, and anionic dermcidin [23].

Antimicrobial potency shows a marked reduction against biofilms of Gram-negative bacteria and the fungus $C$. tropicalis. Reduced activity against biofilm forms of Gram-negative bacteria has also been demonstrated by Chan and colleagues [24]. They observed that cationic antimicrobial peptides, over a specific hydrophobicity threshold aided by the presence of tryptophan and basic lysine residues, bound to alginate, the main exopolysaccharide matrix substance of $P$. aeruginosa. Binding occurred to such an extent that the hydrophilic alginate polymer behaves as an "auxiliary membrane" protecting the biofilm bacteria from the action of cationic peptides. The biofilm form of the strain of P. aeruginosa (PAO1) utilised in this study is non-mucoid and thus observations of the extracellular polymeric substances present in P. aeruginosa (PAO1) show that the main carbohydrate constituents are glucose, mannose and rhamnose not the alginic acid components mannuronate or guluronate [25]. Therefore other resistance mechanisms must exist to explain the relative large increase in MIC, MBC and MBEC values obtained in Table 1. Gramnegative bacteria have evolved the ability to alter the composition of their outer membrane through the modification of lipopolysaccharide molecules [26]. Modification occurs via upregulation of the independently acting PhoPQ and PmrAB two-component transduction systems resulting in an increased tolerance to cationic antimicrobial peptides and may also prevent recognition by the host's immune response. Research by Mulcahy and colleagues has 
shown extracelluar DNA, a primary constituent of the biofilms of Gram-negative microorganisms such as $P$. aeruginosa, to chelate cations and cationic antimicrobial peptides resulting in a 2560 -fold increase in resistance to the cationic antimicrobial peptide polymixin B [27]. Multidrug resistant pumps are present in many forms of bacteria, particularly Gramnegatives and fungi, providing a means by which $P$. aeruginosa, E. coli and C. tropicalis could potentially pump antimicrobials out of their cells allowing resistance to develop against cationic and conventional antimicrobials, thereby increasing observed MIC, MBC, MFC and MBEC values [28].

Cell toxicity was assessed via a MTT assay using human keratinocyte (HaCaT) cell lines. No significant toxicity was demonstrated for any of the peptides up to $1000 \mu \mathrm{g} / \mathrm{ml}$ (Figure 7). HaCaT cells retained significant viability when treated with modified peptides at all concentrations proving they are selective for microbial cells rather than mammalian cells at similar concentrations. Cinnamic-Orn-Orn-Trp-Trp-NH2, 3,5-dimethoxy-4hydroxycinnamic-Orn-Orn-Trp-Trp-NH2, 3-(4-hydroxphenylpropionic)-Orn-Orn-Trp-Trp$\mathrm{NH}_{2}$, $p$-anisic-Orn-Orn-Trp-Trp- $\mathrm{NH}_{2}$ and 6-maleimidocaproic-Orn-Orn-Trp-Trp- $\mathrm{NH}_{2}$ demonstrated no significant haemolysis up to concentrations of $1000 \mu \mathrm{g} / \mathrm{ml}$ (Figure 8). These cationic peptides bind preferentially to the negatively charged phospholipid bilayer of bacterial cells [6]. This is advantageous with regard to reducing toxicity in any potential therapeutic environment. The structure of human erythrocyte membranes have shown that they contain a large number of highly negatively charged sialic acid molecules present in the glycocalyx layer as glycosphingolipids and glycoproteins, projecting from the erythrocyte surface [29]. These may prove to be potential binding sites for cationic antimicrobials. Regardless of this, binding and permeation are much more effective in bacteria than in eukaryotic glycocalyx of erythrocytes as peptides find it harder to cross the carbohydratebased barrier. The majority of non-haemolytic peptides cannot cross the membrane due to a low affinity for the zwitterionic phospholipid bilayer. Cationic antimicrobial peptide's affinity for acidic phospholipids tends to be a lot higher than for zwitterionic phospholipids as demonstrated [30]. Selectivity for biofilm forms of Gram-positive bacteria is also greater than for eukaryotic cells as demonstrated by complete eradication of biofilms occurring at $\mu \mathrm{g} / \mathrm{ml}$ concentrations, with no significant cytotoxicity demonstrated within this range. 


\section{Conclusions}

In this paper, we explored the in vitro antimicrobial properties of ultrashort cinnamon-peptide hybrids against the more resistant biofilm bacterial phenotype associated with medical device infections. The use of ultrashort peptide variants and the attachment of hydrophobic bulk, using naturally occurring molecules such as cinnamic acid derivatives, has large potential for scale-up and translation by the pharmaceutical industry. This will enable the creation of new libraries of effective peptide-based antimicrobial drugs. These molecules compare favourably to larger peptides and proteins due to increased ease of synthesis and reduced production costs, without compromising function. We found cinnamic acid peptide-based molecules to be selective for Gram-positive planktonic and biofilm bacteria and may serve as narrow spectrum antibiotics for targeting Gram-positive infections resistant to standardly employed antibiotics. 3-(4-hydroxphenylpropionic)-Orn-Orn-Trp-Trp- $\mathrm{NH}_{2}$ demonstrated potent activity $(1000 \mu \mathrm{g} / \mathrm{mL})$ against Gram-negative bacterial and fungal (C. tropicalis) biofilms and may serve as a useful molecule to structurally elucidate and improve activity against these problematic pathogens. No significant toxicity was demonstrated using cell culture techniques and a haemolysis assay. These results correlate favourably to previous toxicological results obtained for cinnamic acid-based compounds. Their therapeutic use, particularly in topical/dermatological applications, has been demonstrated to be viable due to the widespread use of cinnamic acid in skin products such as perfumes and as ultra-violet absorbers in sun creams. The cinnamic acid derivatives have also been shown to provide promise in other areas of medicine such as: the treatment of diabetes with stimulation of insulin from pancreatic $\beta$-cells shown; the stimulation of angiogenesis and healing and antitumour activity. This research demonstrates the high potential for the use of such molecules as therapeutics and their potential to be of benefit to limit the increasing spectre of antimicrobial resistance, particularly in device related infection.

\section{References}

1. Bryers J.D. Medical biofilms. Biotechnol. Bioeng. 2008; 100: 1-18.

2. Ioannou C.J, Hanlon G.W, Denyer S.P. Action of disinfectant quaternary ammonium compounds against Staphylococcus aureus. Antimicrob. Agents. Chemother. 2007; 51: 296306.

3. Laverty G, Gorman S.P, Gilmore, B.F. The potential of antimicrobial peptides as biocides. Int. J. Mol. Sci. 2011; 12: 6566-6596. 
4. Strom M.B, Haug B.E, Skar M.L, Stensen W, Stiberg T, Svendsen J.S. The pharmacophore of short cationic antibacterial peptides. J. Med. Chem. 2003; 46: 1567-1570. 5. Bisht G.S, Rawat D.S, Kumar A, Kumar R, Pasha S. Antimicrobial activity of rationally designed amino terminal modified peptides. Bioorg. Med. Chem. Lett. 2007; 17: 4343-4346. 6. Laverty G, McLaughlin M, Shaw C, Gorman S.P, Gilmore B.F. Antimicrobial activity of short, synthetic cationic lipopeptides. Chem. Biol. Drug. Des. 2010; 75: 563-569.

7. Laverty G, Gorman S.P, Gilmore B.F. Biofilm eradication kinetics of the ultrashort lipopeptide $\mathrm{C}_{12}$-Orn-Orn-Trp-Trp- $\mathrm{NH}_{2}$ utilizing a modified MBEC assay. Chem. Biol. Drug. Des. 2015; 85: 645-652.

8. Figueroa-Espinoza M.C, Villeneuve P. Phenolic acids enzymatic lipophilization. J. Agric. Food. Chem. 2005; 53: 2779-2787.

9. Naz S, Ahmad S, Ajaz Rasool S, Asad Sayeed S, Siddiqi R. Antibacterial activity directed isolation of compounds from Onosma hispidum. Microbiol. Res. 2006; 161: 43-48.

10. Mohammadzadeh S, Shariatpanahi M, Hamedi M, Ahmadkhaniha R, Samadi N, Ostad S.N. Chemical composition, oral toxicity and antimicrobial activity of Iranian propolis. Food. Chem. 2007; 103: 1097-1103.

11. Yoya G.K, Bedos-Belval F, Constant P, Duran H, Daffe M, Baltas M. Synthesis and evaluation of a novel series of pseudo-cinnamic derivatives as antituberculosis agents. Bioorg. Med. Chem. Lett. 2009; 19: 341-343.

12. Rastogi N, Domadia P, Shetty S, Dasgupta D. Screening of natural phenolic compounds for potential to inhibit bacterial cell division protein FtsZ. Indian. J. Exp. Biol. 2008; 46: 783787.

13. Truchado P, López-Gálvez F, Gil M.I, Tomás-Barberán F.A, Allende A. Quorum sensing inhibitory and antimicrobial activities of honeys and the relationship with individual phenolics. Food. Chem. 2009; 115: 1337-1344.

14. Mann C.M, Cox S.D, Markham J.L. The outer membrane of Pseudomonas aeruginosa NCTC 6749 contributes to its tolerance to the essential oil of Melaleuca alternifolia (tea tree oil). Lett. Appl. Microbiol. 2000; 30: 294-297.

15. Tesaki S, Tanabe S, Ono H, Fukushi E, Kawabata J, Watanabe M. 4-Hydroxy-3nitrophenylacetic and sinapic acids as antibacterial compounds from mustard seeds. Biosci. Biotechnol. Biochem. 1998; 62: 998-1000.

16. Avila H.P, Smania Ede F, Monache F.D, Smania A. Structure-activity relationship of antibacterial chalcones. Bioorg. Med. Chem. 2008; 16: 9790-9794. 
17. Friedrich C.L, Moyles D, Beveridge T.J, Hancock R.E. Antibacterial action of structurally diverse cationic peptides on Gram-positive bacteria. Antimicrob. Agents.

Chemother. 2000; 44: 2086-2092.

18. Gurkok G, Altanlar N, Suzen S. Investigation of antimicrobial activities of indole-3aldehyde hydrazide/hydrazone derivatives. Chemotherapy. 2009; 55: 15-19.

19. Peters C, Wagner M, Volkert M, Waldmann H. Bridging the gap between cell biology and organic chemistry: chemical synthesis and biological application of lipidated peptides and proteins. Naturwissenschaften. 2002; 89: 381-390.

20. Lopez-Garcia B, Marcos J.F, Abad C, Perez-Paya E. Stabilisation of mixed peptide/lipid complexes in selective antifungal hexapeptides. Biochim. Biophys. Acta. 2004; 1660: 131137.

21. Cudic M, Otvos L. Intracellular targets of antibacterial peptides. Curr. Drug. Targets. 2002; 3: 101-106.

22. Marr A.K, Gooderham W.J, Hancock R.E. Antibacterial peptides for therapeutic use: obstacles and realistic outlook. Curr. Opin. Pharmacol. 2006; 6: 468-472.

23. Vuong C, Voyich J.M, Fischer E.R, Braughton K.R, Whitney A.R, DeLeo F., Otto M. Polysaccharide intercellular adhesin (PIA) protects Staphylococcus epidermidis against major components of the human innate immune system. Cell. Microbiol. 2004; 6: 269-275.

24. Chan C, Burrows L.L, Deber C.M. Helix induction in antimicrobial peptides by alginate in biofilms. J. Biol. Chem. 2004; 279: 38749-38754.

25. Wozniak D.J, Wyckoff T.J, Starkey M, Keyser R, Azadi P, O'Toole G.A, Parsek, M.R. Alginate is not a significant component of the extracellular polysaccharide matrix of PA14 and PAO1 Pseudomonas aeruginosa biofilms. Proc. Natl. Acad. Sci. USA. 2003; 100: 79077912.

26. Folkesson A, Haagensen J.A, Zampaloni C, Sternberg C, Molin S. Biofilm induced tolerance towards antimicrobial peptides. PLoS One. 2008; 3: e1891.

27. Mulcahy H, Charron-Mazenod L, Lewenza S. Extracellular DNA chelates cations and induces antibiotic resistance in Pseudomonas aeruginosa biofilms. PLoS. Pathog. 2008; 4: e1000213.

28. Li X.Z, Nikaido H. Efflux-mediated drug resistance in bacteria. Drugs. 2004; 64: 159204.

29. Viitala J, Jarnefelt J. The red cell surface revisited. Trends. Biochem. Sci. 1985; 10: 392395. 
30. Kamimori H, Blazyk J, Aguilar M.I. Lipid membrane-binding properties of tryptophan analogues of linear amphipathic beta-sheet cationic antimicrobial peptides using surface plasmon resonance. Biol. Pharm. Bull. 2005; 28: 148-150. 
Table 1: The MIC, MBC, MFC and MBEC of cinnamic-Orn-Orn-Trp-Trp-NH2, 3,5-dimethoxy-4-hydroxycinnamic-Orn-Orn-Trp-Trp-NH2, 3(4-hydroxphenylpropionic)-Orn-Orn-Trp-Trp- $\mathrm{NH}_{2}$, p-anisic-Orn-Orn-Trp-Trp- $\mathrm{NH}_{2}$, 6-maleimidocaproic-Orn-Orn-Trp-Trp-NH 2 against MRSE (ATCC 35984), S. aureus (ATCC 29213), MRSA (ATCC 43300), P. aeruginosa (PAO1) and E. coli (NCTC 8196)

\begin{tabular}{|c|c|c|c|c|c|c|c|c|c|c|c|c|c|c|c|c|c|c|}
\hline \multirow{3}{*}{$\begin{array}{l}\text { Peptide } \\
\text { (all concentrations } \\
\text { expressed as } \mu \mathrm{g} / \mathrm{mL} \text { ) }\end{array}$} & \multicolumn{18}{|c|}{ Microorganism } \\
\hline & \multicolumn{3}{|c|}{$\begin{array}{l}\text { MRSE (ATCC } \\
\text { 35984) }\end{array}$} & \multicolumn{3}{|c|}{$\begin{array}{l}\text { S. aureus } \\
\text { (ATCC 29213) }\end{array}$} & \multicolumn{3}{|c|}{$\begin{array}{l}\text { MRSA (ATCC } \\
\text { 43300) }\end{array}$} & \multicolumn{3}{|c|}{$\begin{array}{l}\text { P. aeruginosa } \\
\text { (PAO1) }\end{array}$} & \multicolumn{3}{|c|}{ E. coli (NCTC 8196) } & \multicolumn{3}{|c|}{$\begin{array}{l}\text { C. tropicalis (NCTC } \\
\text { 7393) }\end{array}$} \\
\hline & MIC & $\mathrm{MBC}$ & MBEC & MIC & MBC & MBEC & MIC & MBC & MBEC & MIC & MBC & MBEC & $\mathrm{MIC}$ & $\mathrm{MBC}$ & MBEC & MIC & MFC & MBEC \\
\hline $\begin{array}{l}\text { Cinnamic-Orn-Orn-Trp- } \\
\text { Trp-NH }\end{array}$ & 125 & 125 & 1000 & 125 & 125 & 500 & 125 & 125 & 1000 & 125 & 250 & $>1000$ & 250 & 250 & $>1000$ & 125 & 125 & $>1000$ \\
\hline $\begin{array}{l}\text { 3,5-dimethoxy-4- } \\
\text { hydroxycinnamic-Orn- } \\
\text { Orn-Trp-Trp-NH }\end{array}$ & 125 & 125 & 500 & 62.5 & 125 & $>1000$ & 250 & 250 & 500 & 250 & 250 & $>1000$ & 250 & 250 & $>1000$ & 62.5 & 125 & $>1000$ \\
\hline $\begin{array}{l}\text { 3-(4- } \\
\text { hydroxphenylpropionic)- } \\
\text { Orn-Orn-Trp-Trp-NH }{ }_{2}\end{array}$ & 125 & 125 & 125 & 125 & 250 & 250 & 125 & 125 & 125 & 125 & 125 & $>1000$ & 125 & 125 & 1000 & 125 & 250 & 1000 \\
\hline $\begin{array}{l}\text { p-anisic-Orn-Orn-Trp- } \\
\text { Trp-NH } 2\end{array}$ & 125 & 250 & 250 & 62.5 & 125 & 500 & 250 & 250 & 250 & 250 & 250 & $>1000$ & 500 & 500 & $>1000$ & 125 & 125 & $>1000$ \\
\hline $\begin{array}{l}\text { 6-maleimidocaproic- } \\
\text { Orn-Orn-Trp-Trp-NH } 2\end{array}$ & 125 & 125 & 125 & 125 & 125 & 125 & 250 & 500 & 500 & 250 & 250 & $>1000$ & 500 & 1000 & $>1000$ & 62.5 & 125 & $>1000$ \\
\hline
\end{tabular}


